\title{
O estado nutricional de crianças Yanomami do Médio Rio Negro, Amazônia
}

\author{
Yanomami children's nutritional status in the middle \\ Rio Negro, Brazilian Amazônia
}

Jacques Istria ${ }^{1}$ e Pierre Gazin ${ }^{2}$

\begin{abstract}
Resumo O estado nutricional de 290 crianças, desde o nascimento até a idade de uns seis anos, da população Yanomami do Médio Rio Negro, Amazonas, foi observado em 1998 e 1999. Essa população tem um modo de viver tradicional e dispõe de um largo espaço para as atividades de caça e de colheita. O índice peso/altura foi comparado aos valores de referência do National Center for Health Statistics. Todas essas crianças são de pequena morfologia. Uma desnutrição (índice $\leq-2$ SD) foi observada em 20 delas, ou seja $7 \%$, cinco apresentando uma forma grave $(\leq-3 S D)$. A importância dos contatos exteriores não parece influenciar significativamente nas diferenças que existem entre as comunidades. Esses dados descrevem uma situação sem penúria de alimentação. Os casos de desnutrição parecem ser o resultado conjunto de infecções e de uma situação particular de rejeição do grupo.
\end{abstract}

Palavras-chaves: Estado nutricional. Yanomami. Amazonas. Brasil. Epidemiologia.

Abstract The nutritional status of 290 Yanomami Amerindians children, from birth to about six year-olds, living in the middle Rio Negro, Brazilian Amazonia, has been studied in 1998 and 1999 using the weight-for-height. All of them were of low stature. Twenty malnourished (7\%), defined as below two standard deviations of NCHS' data, have been observed. Five of them showed a severe malnutrition $(\leq-3 S D)$. Differences appeared between the communities, however without evident connection with the practices of these groups and their contacts with the outside. These data indicate a lack of scarcity in this population who preserves a traditional way of life and disposes of a large space for gathering and hunting. The cases of malnutrition are probably a conjoined consequence of infectious attacks in children and of a special bad status in their group.

Key-words: Nutritional status. Yanomami. Amazonia. Brazil. Epidemiology.

O estudo inscreve-se no programa de cooperação celebrado entre a Fundação Nacional do Índio (FUNAI), a Fundação Nacional da Saúde (FNS) e nossa equipe, entre1995 e 1999, para melhorar e promover a saúde das comunidades alvos. Ele corresponde também à vigilância do risco de penúria como conseqüência de uma relativa seca na zona de referência em 1998. O estado nutricional de crianças índias da etnia Yanomami do Rio Negro (Amazonas) foi observado pela medida de dados antropométricos. Essa população, cerca de 1500 indivíduos, vive nas bacias dos rios Marauiá e Padauirí, dois afluentes da margem esquerda do médio Rio Negro, numa terra indígena delimitada e localizada perto da fronteira entre o Brasil e a Venezuela (Figura 1). A região ficou muito isolada até os anos 60 . Ainda hoje, os contatos com o exterior estão limitados a alguns indivíduos (agentes da Fundação Nacional de Saúde, funcionários da Fundação Nacional do Índio, equipes de saúde, pessoal de uma missão salesiana no Marauiá e de uma missão evangelista no Padauirí). Os grupos do baixo Marauiá têm um contato regular com a pequena cidade de Santa Isabel do rio Negro. Não existem garimpeiros nessa área. A população vive agrupada em aldeias. Tratam-se de reuniões temporárias de clãs dentro do mesmo território. O modo normal de uso dos recursos inclui jornadas para acampamentos secundários onde são exploradas outras terras (produção de mandioca e bananas essencialmente) assim como, terrenos de coleta e de caça que têm sido deixados em recuperação. A superfície cultivada por indivíduo é da ordem de 0,05 ha, o espaço para a coleta e a caça da ordem de $10 \mathrm{~km}^{2}$. Uma comunidade de 120 indivíduos precisa então de uma área de $1200 \mathrm{~km}^{2}$. Nas condições normais, a comida geralmente é suficiente e rica em proteínas animais ${ }^{1}$. Apesar disso, períodos de penúria podem surgir. A população é jovem, cerca da metade tendo menos de 16 anos, e se encontra atualmente em crescimento.

1. Instituto pelo Desenvolvimento Sanitário em Meio Tropical, São Gabriel da Cachoeira, AM, Brasil. 2. Institut de Recherche pour le Développement, Paris, França.

Endereço para correspondência: Dr. Jacques Istria. Instituto pelo Desenvolvimento em Meio Tropical. Caixa Postal 91, 69750-000 São Gabriel da Cachoeira, AM. E-mail: jistria@ hotmail.com

Recebido para publicação em 18/01/2001. 


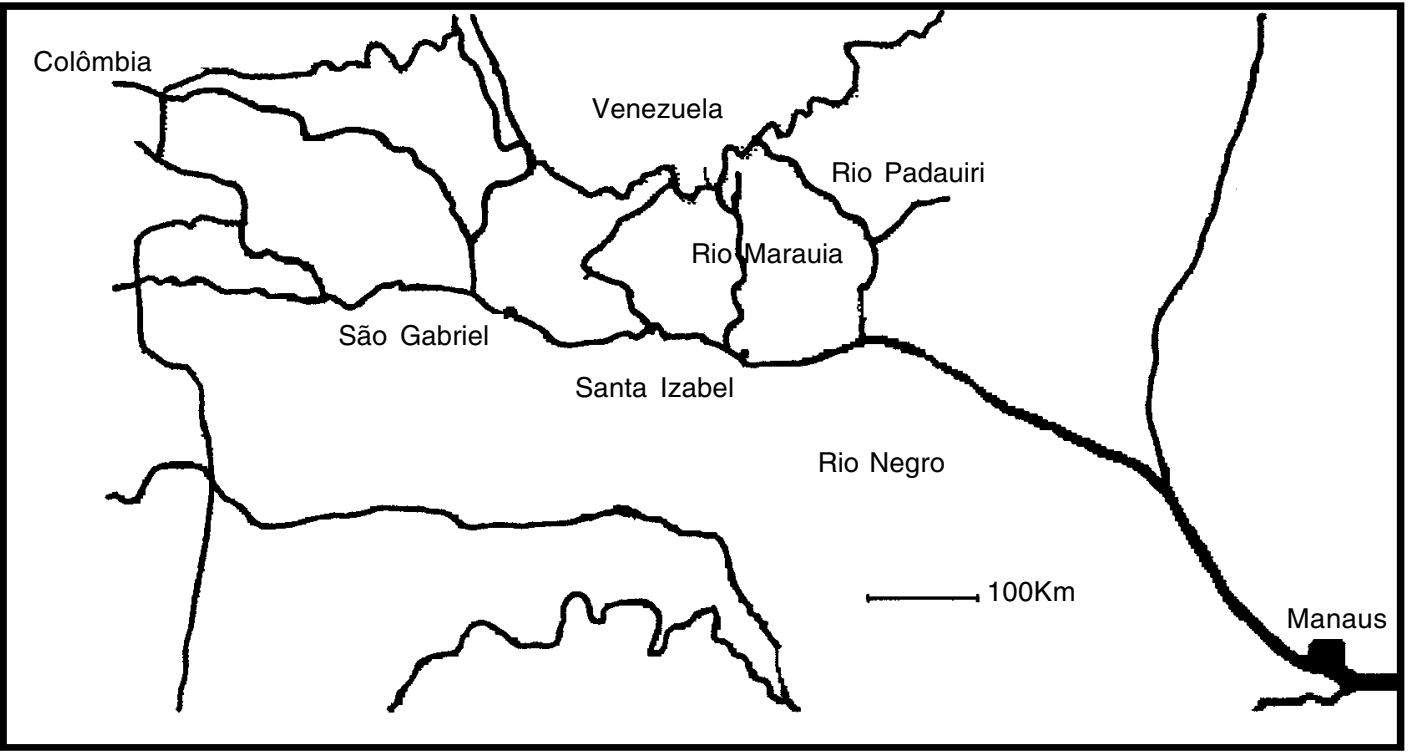

Figura 1- Mapa esquemático do Médio Rio Negro, Amazônia.

\section{MATERIAL E MÉTODOS}

Os inquéritos foram realizados no Marauiá em Agosto de 1998 e no Padauirí em Julho de 1999. O peso e a altura de todas as crianças presentes, do nascimento até a idade aproximada de seis anos, foram medidos sempre pelo mesmo observador. $O$ peso foi medido com uma balança suspensa de marca Salter (precisão de $100 \mathrm{~g}$ ) e a altura com uma régua antropométrica vertical, exceto os mais jovens, observados em decúbito. Os perímetros dos braços (PB) foram medidos com os braços extendidos. Nessa população sem registro civil, as idades dependem das memórias. Estabelecidas pelos investigadores segundo as afirmações dos pais, elas não são precisas. Assim, o índice peso/altura foi o único usado para definir as situações de desnutrição. Os dados foram comparados aos valores de referência do Nacional Center for Health Statistics. O limite de -2 standard deviations $(S D)$ foi escolhido para definir um estado de desnutrição simples, de -3 $S D$ para uma forma grave. A significação do PB foi estudada nos 6-12 meses $^{8}$.

\section{RESULTADOS}

As onze aldeias da área foram visitadas. Por enquanto, a aldeia de Pukima foi pouco estudada, já que a maioria dos moradores encontravam-se então num acampamento de acesso muito difícil. As observações envolvem 290 crianças (136 meninas e 154 meninos) ou seja cerca de $80 \%$ dos grupos estudados. A evolução dos pesos em relação às alturas é regular com um coeficiente de correlação de 0,95.
Nenhum caso de kwashiorkor foi observado. Vinte crianças apresentavam um déficit misto protéico-calórico (9 meninas e 11 meninos). Elas tinham uma idade média de dois anos e meio (Tabelas 1 e 2). Cinco delas apresentavam uma forma grave. Vinte crianças de aproximadamente 6 a 12 meses tinham um PB inferior a $12,5 \mathrm{~cm}$. Três delas estavam desnutridas segundo os critérios do índice peso/altura.

\section{DISCUSSÃO}

O tradicional estilo de vida dos índios amazonenses permite-Ihes geralmente uma alimentação rica em proteínas animais e quantitativamente suficiente. Essas quantidades às vezes são subestimadas pelos pesquisadores devido a um importante consumo nos lugares de coleta 4 . Segundo a literatura científica, a desnutrição é rara nessas crianças de pequeno tamanho mas que apresentam um desenvolvimento regular. Ela é ausente em alguns grupos e não ultrapassa $10 \%$ em outros. Nem avitaminoses nem bócios por insuficiência de iodo são observados apesar da situação continental ${ }^{2}{ }^{5}$. Até hoje, os Yanomami observados nessa pesquisa mantêm-se como caçadores e coletores realizando um pouco de agricultura. A alimentação é diversificada, baseada em bananas, mandioca, frutas de palmeiras e de diversas árvores da floresta, leguminosas e raízes do mato. Proteínas animais vêm da caça (roedores, porcos, antas, viados, jacarés, macacos, aves), de um pouco de peixes e de pequenos animais de coleta (larvas de cupins, rãs, 
Tabela 1 - Repartição do índice peso/altura de crianças Yanomami dos rios Marauiá e Padauirí em 1998-1999, em comparação com os valores de referência do NCHS.

\begin{tabular}{lccr}
\hline & \multicolumn{2}{c}{ Sexo } & \\
\cline { 2 - 3 } Repartição do índice & masculino & feminino & Total \\
\hline$<-4$ SD & 1 & 1 & 2 \\
]-4 SD, , -3 SD] & 1 & 2 & 3 \\
]-3 SD, , -2 SD] & 9 & 6 & 15 \\
]-2 SD, , -1 SD] & 27 & 27 & 54 \\
]-1 SD, , O SD] & 72 & 54 & 126 \\
[0 SD, , +1 SD[ & 36 & 36 & 72 \\
[+1 SD, , +2 SD[ & 5 & 7 & 12 \\
[+2 SD, , +3 SD[ & 3 & 2 & 5 \\
\hline$>+3$ SD & 0 & 1 & 1 \\
\hline Total & 154 & 136 & 290 \\
\hline
\end{tabular}

caranguejos, lagartos). A amamentação é efetuada até aproximadamente a idade de dois anos, associada à introdução precoce de banana, carne e peixe.

Os adultos desse grupo Yanomami são de morfologia pequena, apresentando uma média de $154 \mathrm{~cm}$ e $50 \mathrm{~kg}$ para os homens, de $144 \mathrm{~cm}$ e $44 \mathrm{~kg}$ para as mulheres ${ }^{3}$, uma situação freqüente nos aborígenes das matas tropicais úmidas ${ }^{4}$. Por enquanto, os valores de referência do NCHS são considerados aceitáveis para as crianças desses grupos $^{67}$. Os índices peso/altura evidenciam que as crianças não são gordas. Somente $2 \%$ delas têm um peso/altura acima de +2 SD e todas elas foram encontradas no grupo dos amamentados. Os desnutridos são pouco numerosos, $7 \%$. Um quarto deles sofre danos graves. Não aparece diferença nem entre sexos, nem entre as duas áreas estudadas. Um PB acima de $12,5 \mathrm{~cm}$ nos $6-12$ meses é associado a um bom estado nutricional.

Essas observações indicam uma boa disponibilidade da comida nessas comunidades, pelo menos na época dos inquéritos. A população não relata ocorrência de penúria durante esses últimos anos. O uso de outros indicadores teria permitido um estudo retroativo do estado nutricional ${ }^{9}$. Os cinco casos graves observados seriam provavelmente o resultado de uma patologia infecciosa recente (malária, diarréia, infecção pulmonar) e/ou de uma posição particular da criança dentro do seu grupo (criança rejeitada, casal separado). As condições de vida podem também ter uma influência: os deslocamentos durante várias semanas na floresta para criar uma nova roça, coletar frutas, visitar parentes, ou seja antes de qualquer safra, com condições precárias de moradia, são momentos difíceis.

Existem diferenças relativas às várias aldeias em relação aos contatos exteriores. Irapagé, localizado no jusante do rio Marauiá, tem mais
Tabela 2 - Estado nutricional de crianças Yanomami dos rios Marauiá e Padauirí em 1998-1999 segundo o índice peso/altura.

\begin{tabular}{lrrr}
\hline & & \multicolumn{2}{c}{ Crianças } \\
\cline { 3 - 4 } Comunidades & Indivíduos & examinadas & desnutridas \\
\hline Marauiá & & & \\
$\quad$ Irapagé & 95 & 21 & 0 \\
Xamatá & 118 & 43 & 6 \\
Ixima & 138 & 30 & 6 \\
Pukima & 130 & 5 & 0 \\
Pohoró & 385 & 96 & 4 \\
Raita & 28 & 6 & 0 \\
Kona & 108 & 22 & 0 \\
Total Marauiá & 1002 & 223 & 16 \\
Padauiri & & & \\
$\quad$ Lahaka & 55 & 6 & 1 \\
Pahana & 61 & 9 & 1 \\
Juruparú & 62 & 9 & 1 \\
$\quad$ Marari & 247 & 43 & 1 \\
Total Padauiri & 425 & 67 & 4 \\
\hline
\end{tabular}

contatos e consome algumas comidas compradas (arroz, feijão, enlatados, açúcar, sal). Pohoró é uma grande comunidade isolada que se fixou na proximidade de uma missão. Em 1998, ela recebia uma ajuda alimentar, talvez por isso as atividades agrícolas sofreram algum prejuízo além da seca. Os outros grupos do Marauiá não recebem esse tipo de ajuda e persistem na prática dos deslocamentos para lugares fartos em caça e produtos de coleta. As taxas das crianças desnutridas são diferentes de uma aldeia a outra: $0 \%$ em Irapagé, $4 \%$ em Pohoró, $12 \%$ no conjunto Xamatá, Raita, Ixima e Kona. Os efetivos reduzidos não autorizam em deduzir uma conclusão categórica sobre essas diferenças.

Conclusão. As observações antropométricas das crianças da população indígena do médio Rio Negro mostram que em 1998-1999 o estado nutricional estava bom para a maioria delas. A percentagem de desnutridos, todos de forma mista protéico-calórica, estava de $7 \%$, incluindo $2 \%$ de formas graves. Os desnutridos parecem ser aqueles que sofrem uma situação particular de doença e/ou de rejeição pelas famílias. Esses índios Yanomami com um modo tradicional de viver parecem ter acesso a uma alimentação suficiente em quantidade e qualidade, o que se manifesta na constatação da pequena proporção de desnutridos. A população não vive na abundância mas sabe achar os recursos alimentares à partir do seu meio ambiente com a sua própria maneira de exploração. Comidas de fora apareceram em alguns grupos. Essa nova situação não está associada a uma deterioração do estado nutricional nestes grupos.

\section{AGRADECIMENTOS}

Os autores agradecem ao Dr. Eric Benefice, nutricionista do IRD, por sua leitura crítica desse manuscrito. 


\section{REFERÊNCIAS BIBLIOGRÁFICAS}

1. Albert B, Gomez GG. Saúde Yanomami : um manual etnolinguístico. Editora Museu Goeldi, Belém, 1997.

2. Benefice $E$, Barral $H$, Romo-Nunez Z Ecologie de la santé et de la nutrition en Amazonie Equatorienne (Province de Napo). I: Les Indiens Sionas-Sécoyas du Rio Aguarico. Bulletin de la Société de Pathologie Exotique 82: 531-543,1989.

3. Bourgoin PE. Enquête épidémiologique des communautés Yanomami du rio Cauaburis, Parc Nacional de la Neblina, Amazonas, Brésil. Tese de Medicina, Marseille, França, 1998,

4. Dufour DL. Diet and nutritional status of Amerindians: a review of litterature. Cadernos de Saúde Publica 7: 481-502, 1991.

5. Dufour DL. Nutritional ecology in the tropical rain forests of Amazonia. American Journal of Human Biology 4: 197-207, 1992.
6. Kow F, Geissler C, Balasubramaniam E. Are international anthropometric standards appropriate for developping countries? Journal of Tropical Pediatrics 37: 37-44, 1991.

7. Martins SJ, Menezes RC. A mathematical approach for estimating reference values for weight-for-age, weight-for-height and heightfor-age. Growth Development Aging 61:3-10, 1997.

8. Pust $\mathrm{R}$, Johnson $\mathrm{P}$, Lautenschlager J. Detecting malnutrition at age 6-12 months: international comparisons of arm circumference versus standard anthropometry. Journal of Tropical Pediatrics 38: 240-246, 1992.

9. Santos RV, Coimbra Junior CE. Hardships of contact: enamel hypoplasias in Tupi-Monde Amerindians from the Brazilian Amazonia. American Journal of Physic Anthropology 109: 111-127, 1999. 